\title{
Infecção por COVID-19 em Transplante de Coração: Relatos de Caso
}

\author{
COVID-19 Infection in Heart Transplantation: Case Reports
}

\author{
Ligia Espinoso Schtruk, ${ }^{1}$ Jacqueline Miranda, ${ }^{1}$ Vitor Salles, ${ }^{1}$ Ana Sales, ${ }^{1}$ Luciana Lobbe, ${ }^{1}$ Vaisnava Cavalcante, ${ }^{1}$ \\ Elisangela Reis, ${ }^{7}$ Sharon Kugel, ${ }^{1}$ Bruno Marques, ${ }^{1}$ Gabrielle Carvalho, ${ }^{1}$ Ruth Maia, ${ }^{1}$ Filipe Oliveira dos Reis, ${ }^{1}$ \\ Danielle Rodrigues ${ }^{1}$ \\ Instituto Nacional de Cardiologia - Serviço de Insuficiência Cardíaca e Transplante, ${ }^{1}$ Rio de Janeiro, RJ - Brasil
}

No final de 2019, a infecção por um novo coronavírus, causando síndrome respiratória aguda grave, foi relatada em Wuhan, na China. ${ }^{1}$ Em 11/03/2020, a COVID-19 foi caracterizada pela Organização Mundial da Saúde como uma pandemia. ${ }^{2} \mathrm{O}$ Brasil notificou o primeiro caso na América Latina em 26/02/2020. ${ }^{2}$ Considerando o curto período de tempo desde o início da pandemia, foram poucos os casos relatados de infecção em receptores de transplante cardíaco ${ }^{3}$. Pouco se sabe sobre as manifestações clínicas e a evolução do quadro neste grupo de pacientes.

\section{Relatos de Caso}

Caso 1: sexo masculino, 47 anos, branco, portador de doença de Chagas, transplante cardíaco em 08/08/2012, sem comorbidades, em uso de tacrolimus (4 mg/dia), micofenolato de sódio (1.440 mg/dia).

Em 12/04/2020, apresentou mialgia, febre, cefaleia, dispneia leve, tosse seca, diarreia e anosmia. Ele mora em uma comunidade com casos confirmados de COVID-19. Em 14/04/2020 (D3 dos sintomas) procurou atendimento de urgência. Exame físico: febril (T. axilar: $38^{\circ} \mathrm{C}$ ), sem instabilidade hemodinâmica (PA: 100 x 60mmHg, FC: 60 bpm), saturação limítrofe de oxigênio $\left(\mathrm{SpO}_{2}: 93 \%\right)$. A gasometria arterial mostrou hipóxia leve. Os demais exames são apresentados na Tabela 1. A tomografia computadorizada (TC) de tórax foi realizada na admissão, evidenciando imagem em vidro fosco bilateral, com distribuição multilobar, predominantemente periférica, com padrão de pavimentação em mosaico, associada a focos e áreas de consolidação. localizado nos lobos inferiores, com envolvimento $<25 \%$ (Figura 1-A). A secreção nasofaríngea foi coletada para o teste RT-PCR SARS-COV2, o qual foi positivo. O paciente foi hospitalizado.

O micofenolato de sódio foi suspenso (trombocitopenia / leucopenia), o tacrolimus foi mantido e a prescrição de anticoagulação profilática iniciada. No 3o dia de internação (D6 dos sintomas), o paciente manteve-se clinicamente estável $\left(94 \% \mathrm{SatO}_{2}\right)$, com febre e piora da imagem radiológica,

\section{Palavras-chave}

Doença de Chagas; Transplante do Coração; Imunossupressão; COVID-19/complicações; Comorbidades.

\section{Correspondência: Ligia Espinoso Schtruk •}

Instituto Nacional de Cardiologia - Serviço de Insuficiência Cardíaca e

Transplante - Rua das Laranjeiras, 374. CEP 22240-006, Laranjeiras, RJ - Brasil E-mail: ligia.imuno@gmail.com

Artigo recebido em 28/05/2020, revisado em 09/06/2020, aceito em 24/06/2020

DOI: https://doi.org/10.36660/abc.20200554 com consolidação em hemitórax direito, e intensificação da opacificação em vidro fosco em hemitórax esquerdo (Figura 1-B). Azitromicina (500 mg/d - 5 dias) e Ceftriaxona ( $2 \mathrm{~g} / \mathrm{d}$ - 7 dias) foram iniciados. No 6 o dia de internação, o nível sérico de tacrolimus era de $4,3 \mathrm{ng} / \mathrm{dL}$ e a dose foi ajustada. No 60 dia de internação (D9 dos sintomas), a febre persistia. A tomografia computadorizada revelou progressão da doença, com comprometimento de $<50 \%$ do parênquima pulmonar (Figura 1-B). Foi iniciada hidroxicloroquina (dose de 400 mg 12/12h 1a / dia, 400 mg/dia- 4 dias). No 6으 dia de hospitalização, a leucopenia/linfopenia/ trombocitopenia melhoraram e o micofenolato de sódio foi reintroduzido. Nessa data, um aumento nos níveis de D-dímero foi observado (<500 ug/L a 2.270 ug/L). O Doppler vascular de membros inferiores não mostrou alterações. Ele recebeu alta hospitalar no $12^{\circ}$ dia de internação, encontrando-se assintomático. Os testes de laboratório são mostrados na Tabela 1.

Caso 2: sexo masculino, 54 anos, branco, com cardiomiopatia dilatada idiopática, submetido a transplante cardíaco em 03/08/2012. Comorbidades: hipertensão arterial sistêmica e artrite gotosa. Ele recebeu tacrolimus ( $2 \mathrm{mg} / \mathrm{dia}$ ) e micofenolato de mofetil (1000 mg/dia).

No dia 11/05/2020 apresentou febre (38 ํㅡ), tosse seca, falta de apetite e astenia. Sua filha tinha os mesmos sintomas. Em 13/05/2020 (D3 dos sintomas) procurou o pronto-socorro, e o exame físico não evidenciou febre ou

Tabela 1 - Exames laboratoriais: hospitalização e alta hospitalar

\begin{tabular}{lcccc}
\hline \multirow{2}{*}{ Exames } & \multicolumn{2}{c}{ Hospitalização } & \multicolumn{2}{c}{ Alta hospitalar } \\
\cline { 2 - 5 } & Caso 1 & Caso 2 & Caso 1 & Caso 2 \\
\hline Sat $\mathrm{O}_{2}(\%)$ & 95 & 94 & 95 & 97 \\
Hemoglobina (g\%) & 14 & 15,2 & 14 & 15,3 \\
Leucócitos $\left(\mathrm{mm}^{3}\right)$ & 1.670 & 7.890 & 9.220 & 7.480 \\
Neutrófilos $\left(\mathrm{mm}^{3}\right)$ & 910 & 6.043 & 5.983 & 5.056 \\
Linfócitos $\left(\mathrm{mm}^{3}\right)$ & 439 & 623 & 1825 & 1264 \\
Plaquetas $\left(\mathrm{mm}^{3}\right)$ & 87.000 & 278.000 & 293.000 & 417.000 \\
PCR* & 2 & 19 & 0,7 & 1,6 \\
Creatinina & 1,07 & 1,04 & 0,95 & 1,16 \\
Ferritina & 400 & 1992 & 1217 & 2208 \\
D-dímero (ug/L) & 310 & 3.000 & 590 & 690 \\
Tacrolimus (ng/dl) & 9,9 & 8,63 & 5,6 & 7,75 \\
\hline
\end{tabular}

${ }^{*}$ PCR: Proteína C-Reativa. 
Figura 1-A

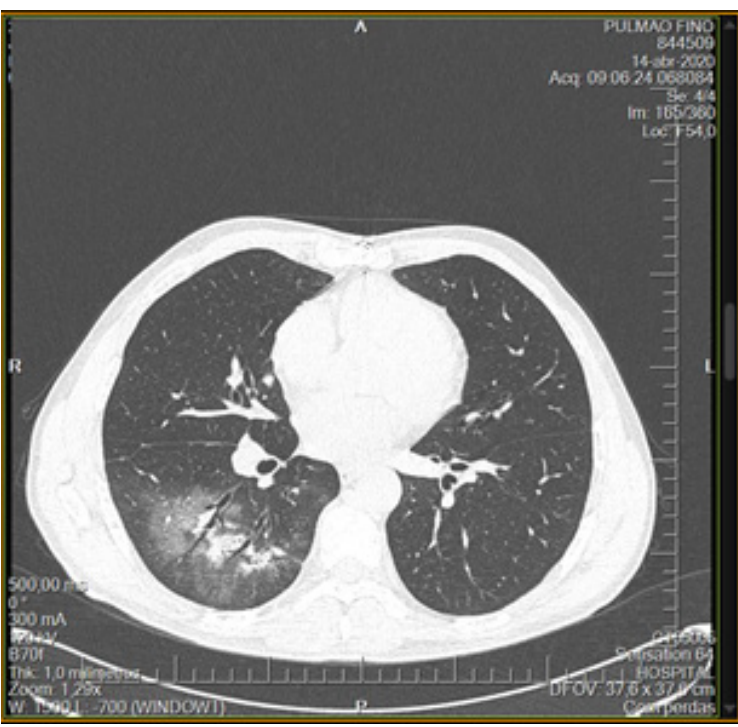

Figura 1-B

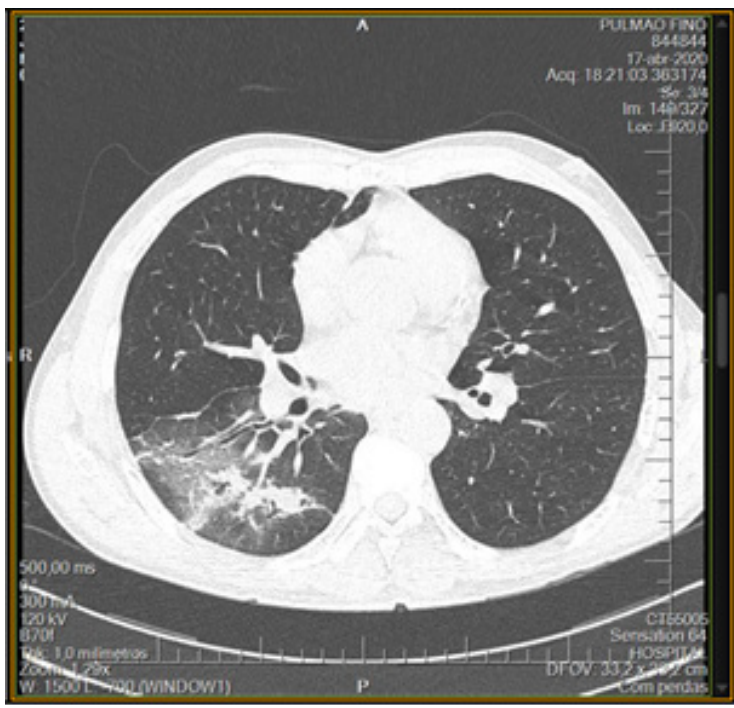

Figura 1-C

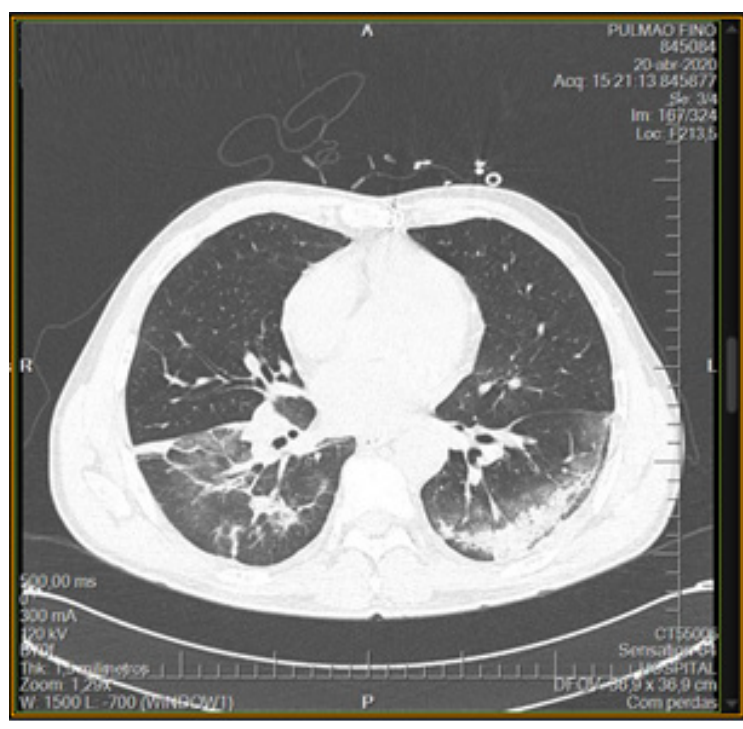

Figura 1 - Caso 1- Tomografia Computadorizada de Tórax. 


\section{Carta Científica}

instabilidade hemodinâmica (PA: 118x 78 mmHg, FC: 86 bpm); saturação de oxigênio ( $\mathrm{SpO}_{2}$ : 94\%), sem dispneia. A gasometria arterial estava normal; os demais exames são apresentados na Tabela 1. A TC de tórax evidenciou áreas de atenuação em vidro fosco bilateralmente, com distribuição periférica predominante, com espessamento septal e alguns focos de consolidação associados, comprometimento $<50 \%$ (Figura 2-A). A secreção nasofaríngea foi coletada para o teste RT-PCR SARS-COV2, o qual foi inconclusivo. O paciente foi hospitalizado. A imunossupressão foi mantida (sem leucopenia/ trombocitopenia). Os exames laboratoriais mostraram parâmetros inflamatórios elevados (Tabela 1) e níveis elevados de D-dímero. Foram prescritas ceftriaxona (2 g/dia- 7 dias), azitromicina (500 mg/dia- 5 dias) e enoxaparina $(0,5 \mathrm{mg} / \mathrm{kg} / \mathrm{dia})$. No 3 o dia de internação (D6 dos sintomas), encontrava-se clinicamente estável (95\% SatO 2 ), sendo o último dia com febre. O ecocardiograma mostrou função sistólica biventricular preservada (FE por Teichholz: $70,4)$. No 6 o dia de hospitalização (D9 dos sintomas) a tomografia computadorizada evidenciou melhora da imagem radiográfica, acometendo menos de $<50 \%$ do parênquima pulmonar (Figura 2-B). Em 18/05/20 uma segunda amostra de secreção nasofaríngea foi coletada para o teste de RTPCR SARS-COV2, o qual permaneceu inconclusivo. O paciente apresentou melhora da linfopenia, redução dos parâmetros inflamatórios e queda progressiva dos níveis de D-dímero. Recebeu alta hospitalar no 10o dia de internação, encontrando-se assintomático. Os testes de laboratoriais são mostrados na Tabela 1.

Figura 2-A

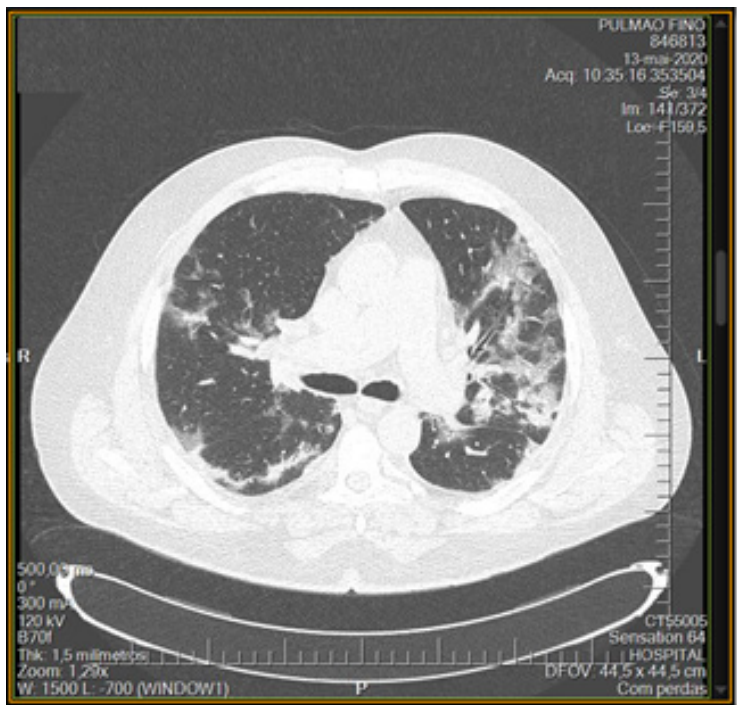

Figura 2-B

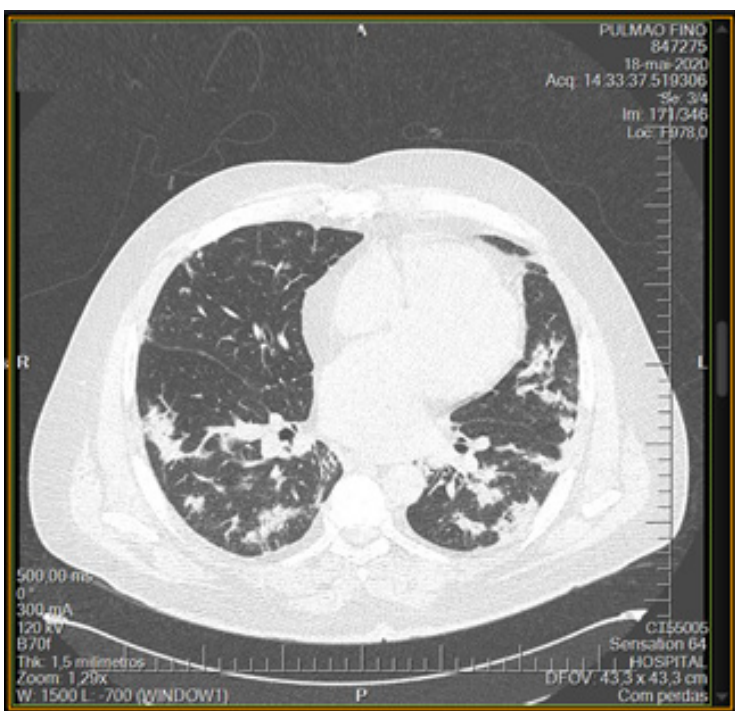

Figura 2 - Caso 2- Tomografia Computadorizada de Tórax. 


\section{Discussão}

A imunossupressão tem sido descrita como fator de risco de maior gravidade na infecção por COVID-19, assim como idade avançada, doenças cardiovasculares, diabetes mellitus, neoplasias e doenças pulmonares crônicas. ${ }^{4}$ Nesses casos, a apresentação clínica foi moderada e semelhante à relatada em pacientes não-imunossuprimidos. ${ }^{4}$ Os resultados inconclusivos do teste de RT-PCR SARS-COV2 de swab nasofaríngeo do Caso 2 estão de acordo com estudos que mostram que apenas $63 \%$ dos testes realizados foram positivos. ${ }^{5}$ Apesar de não haver critérios para hospitalização, de acordo com as recomendações da OMS e do Ministério da Saúde do Brasil, optou-se por indicar a internação, visto que as doenças virais respiratórias representam uma causa importante de morbimortalidade em pacientes imunocomprometidos. ${ }^{1,6,7}$ O caso 1 permaneceu febril até o 10 dia da doença, com leucopenia, linfopenia grave e trombocitopenia, o que nos obrigou a suspender o uso de micofenolato de sódio. Não foi necessário suspender o regime de imunossupressão no Caso 2. Apesar da imagem radiológica e dos marcadores inflamatórios, não houve piora ventilatória ou hipoxemia durante o curso da doença. As imagens tomográficas foram compatíveis com o diagnóstico e, no Caso 2, os parâmetros clínicos e radiológicos permitiram o diagnóstico. ${ }^{8}$ Estudos demonstram a participação imunológica na etiopatogênesis dos distúrbios da coagulação associados à COVID-19. ${ }^{9}$ Os pacientes apresentaram elevação do D-dímero, mas no Caso 1, esse aumento ocorreu mais tarde, no $11^{\circ}$ dia de doença. Eles usaram profilaxia para trombose, e não houve eventos tromboembólicos. Atualmente, não há terapia específica comprovada disponível para COVID-19. ${ }^{9-11}$ O tratamento segue indicações semelhantes às dos pacientes não-transplantados. O regime de hidroxicloroquina foi utilizado com base na eficácia in vitro e dados clínicos sobre o tratamento para COVID-19 no primeiro paciente, mas não no segundo. Essa mudança ocorreu porque, nesta data, os estudos não mostraram evidências de grande eficácia desse medicamento no tratamento da COVID-19. ${ }^{10,11}$ Azitromicina e Ceftriaxona foram utilizadas devido a uma possível associação com pneumonia bacteriana.

\section{Referências}

1. Zhu N, Zhang D, Wang W, Li X, Yang B, Song J, et al. A novel coronavirus from patients with pneumonia in China, 2019. N Engl J Med. 2020;382(8):727-33.

2. Pan American Health Organization / World Health Organization. (WHO). Epidemiological Update: Novel coronavirus (COVID-19). 20 April 2020, Washington, D.C.: PAHO/WHO; 2020. Updated on April 26, 2020. https:// www.paho.org/bra/

3. Fei Li, Jie Cai, Nianguo Dong, First Cases of COVID-19 in Heart Transplantation From China. J Heart Lung Transpl. 2020;39(5):496-7.

4. Wu Z, McGoogan JM. Characteristics of and Important Lessons From the Coronavirus Disease 2019 (COVID-19) Outbreak in China: Summary of a Report of 72314 Cases From the Chinese Center for Disease Control and Prevention. JAMA.2020 Feb 24 (online ahead print) doi: 10.1001/ jama.2020.2648

5. Wang W, Xu Y, Gao R, Lu R, Han K, Wu G, et al. Detection of SARS-CoV-2 in different types of clinical specimens. JAMA. 2020;323(18):1843-4.
Mudanças no regime imunossupressor devem ser analisadas individualmente, de acordo com a evolução de cada caso. A evolução clínica não foi mais grave do que a observada em pacientes não-imunossuprimidos. Estudos são necessários para avaliar se o uso de imunomoduladores poderia atenuar a cascata inflamatória. Nestes casos específicos, não foi observada inflamação exuberante, que poderia estar associada ao uso crônico de imunossupressores.

\section{Contribuição dos Autores}

Concepção e desenho da pesquisa: Schtruk LE, Miranda J; Obtenção de dados: Schtruk LE, Miranda J, Salles V, Cavalcante V, Reis E, Kugel S, Marques B, Carvalho G, Maia R, Reis FO, Rodrigues D; Análise e interpretação dos dados: Schtruk LE, Miranda J, Salles V, Salles A, Lobbe L; Redação do manuscrito: Schtruk LE, Miranda J, Salles V, Salles A, Lobbe L; Revisão crítica do manuscrito quanto ao conteúdo intelectual importante: Schtruk LE, Miranda J, Salles V, Salles A, Lobbe L, Cavalcante V.

\section{Potencial Conflito de Interesses}

Declaro não haver conflito de interesses pertinentes.

\section{Fontes de Financiamento}

O presente estudo não teve fontes de financiamento externas.

\section{Vinculação Acadêmica}

Não há vinculação deste estudo a programas de pósgraduação.

\section{Aprovação Ética e Consentimento Informado}

Este estudo foi aprovado pelo Comitê de Ética do Instituto Nacional de Cardiologia sob o número de protocol 4.081.414. Todos os procedimentos envolvidos nesse estudo estão de acordo com a Declaração de Helsinki de 1975, atualizada em 2013. O consentimento informado foi obtido de todos os participantes incluídos no estudo.
6. Coronavirus Clinical Management Protocol (COVID-19) in Primary Health Care. Brasília: Ministério da Saúde;2020.

7. Michaels MG, La Hoz RM, Danzigerlsakov-Isakov L, Blumberg A, Kumar D, Green M, et al.. Coronavirus disease 2019: Implications of emerging infections for transplantation. Am J Transplant.2020;20(7):1768-72.

8. American College of Radiology. ACR recommendations for the use of chest radiography and computed tomography (CT) for suspected COVID-19 infection. March 22, 2020 [Cited in 2020 Apr 10]. Available from: (https:// www.acr.org/Advocacy-and-Economics/ACR-Position-Statements/ Recommendations -for-Chest-Radiography-and-CT-for-SuspectedCOVID19-Infection).

9. Tang, N, Bai, H, Chen, X, Gong, J, Li, D, Sun, Z. Anticoagulant treatment is associated with decreased mortality in severe coronavirus disease 2019 patients with coagulopathy. J Thromb Haemost. 2020;18:1094-9. 


\section{Carta Científica}

10. Yao X, Ye F, Zhang M, Huang B, Niu P, Liu X, et al. In Vitro Antiviral Activity and Projection of Optimized Dosing Design of Hydroxychloroquine for the Treatment of Severe Acute Respiratory Syndrome Coronavirus 2 (SARSCoV-2) Clin Infect Dis. 2020;71(15):732-9.
11. Gautret $Y$, Lagier JC, Parola P, Hoang VT, Meddeb L, Mailhe M, et al. Hydroxychloroquine and azithromycin as a treatment of COVID-19: results of an open-label nonrandomized clinical trial. Int J Antimicrob Agents. 2020;56(1):10549.

Este é um artigo de acesso aberto distribuído sob os termos da licença de atribuição pelo Creative Commons 